\title{
OUTCOME OF COMPLEMENTING LIVE LECTURES WITH ASYNCHRONOUS LECTURE CAPTURE AND ONLINE CONTENT TO TEACH UNDERGRADUATE ENGINEERING STUDENTS COMPLEX CONCEPTS IN KINEMATICS AND DYNAMICS
}

\author{
Dhariwal, H; Cleghorn, W L \\ Faculty of Applied Science and Engineering, University of Toronto, Ontario Canada \\ harpreet.dhariwal@utoronto.ca
}

\section{INTRODUCTION}

The Mechanical Engineering program at the authors' university includes the course entitled Kinematics and Dynamics of Machines (MIE301), which covers a wide variety of topics of mechanical devices, such as linkages, gears, and cams. The content of the lectures in MIE301 includes a combination of delivering notes in real-time, demonstrating mechanical models, showing computer animations, and playing of video clips.

In September 2010, the Faculty of Applied Science and Engineering, at the University of Toronto introduced a lecture capture initiative to enhance student engagement and student learning. MIE301 taught by one of the co-authors was the first course in the Faculty to have the lectures captured for an entire term. To effectively provide presentations in the lectures of MIE301, the authors developed the Multimedia Enhanced Electronic Teaching System (MEETS). [1] A layout of the MEETS is shown in Figure 1. The EPDDA (i.e., Easel Paper Dispenser Display Adapter) shown in the figure has similarities to the plastic rolls used with an overhead projector. However, in this case, paper rolls are employed. Even when the class size is very large, the MEETS produces visual output to allow intimate demonstrations to the students at distant seats away from the front of the classroom. The MEETS produces signals which are seen and heard during the live lectures and is designed with the capability to integrate well with various lecture capture systems.

All lectures for the course were presented in one section to the entire class of nearly 200 students. In addition, the lectures were captured live in the classroom using the MEETS, and then put online for the students to either listen to the ones they had missed or review those parts which they had trouble understanding.

Engineering courses traditionally require rigorous note taking in the classroom and this often presents a challenge for sometimes missing key points of crucial visual demonstrations. Lecture capture allows flexibility in learning and accommodates the many different learning styles for engineering students. The authors believe it allows the students to focus on the presented material knowing that the full content including all demonstrations of physical models, will be available for review after the lecture. The ability for the engineering students to have full knowledge of the previous lectures and a better understand the content allows them to be further engaged in subsequent lectures.

A survey was administered near the end of the term to gather input from the undergraduate Engineering students who took MIE301. The authors made efforts to make the questions clear and easy to answer. The majority of the questions were multiple choice and the relevancy of the questions was intentional and focused on the lecture capture initiative within the Faculty. This inaugural but significant survey provided relevant feedback from the students to establish general conclusion and positive outcomes of the Faculty lecture capture initiative. The authors believe the data and analysis will contribute to the improvement of the delivery of future Engineering courses.

A survey was administered near the end of the term to gather input from the undergraduate Engineering students who took MIE301. The authors conducted the survey during a lecture at which the attendance was high to ensure that the results were an accurate reflection of the entire class of students. The authors made efforts to make the questions clear and easy to answer. The majority of the questions were multiple choice and the relevancy of the questions was intentional and focused lecture capture initiative within the Faculty. This inaugural but significant survey provided relevant feedback from the students to establish general conclusions and positive outcomes of the lecture capture initiative. The authors believe the data and analysis will contribute to the improvement of the delivery of future Engineering courses.

\section{RESULTS}

The initial analysis of the student survey data was to learn about the impact of lecture capture on the student learning and engagement. To fully understand the effect of the online lecture capture content, it was necessary to determine if the students watched the recorded lectures, how many they watched, and learn about their viewing patterns.

Although the viewing of the online captured lectures was completely optional and was not suggested during the course as a method to supplement the class lectures, the data revealed that $95 \%$ students responded "Yes" when asked if they had watched any of the course content online.

Analyzing this further, the students were asked to quantify the amount of lectures they watched. The data reveal that $75 \%$ preferred to watch some of the lectures, and $20 \%$ watched most or all of the lectures.

The data analysis confirms the student feedback received throughout the term during course office hours and on the online discussion board for the course website. The students in MIE301 commented that the online lectures were excellent supplements to the live lectures. The students were appreciative of the flexibility and confirmed the captured lectures were predominantly used to review parts of the live lecture that were particularly difficult to understand the first time. The students complimented on the indexed navigation of the lecture capture system that allowed the student to on-demand easily skip to the any specific part in the lecture.

The results from our survey confirm this finding on attendance. The MIE301 students were asked if having the lectures available online affected their attendance for the live lectures, and a very high majority of almost $90 \%$ responded that it did not. This finding is consistent with other research in which it was found that the availability of recordings was not seen to impact lecture attendance, although the students showed some tendency to listen to the recording for a missed lecture. [2]

In addition to the results from the questionnaire, the following feedback was obtained from the students through the course website: "Just wanted to say how much I appreciate the effort that goes into capturing the lectures and posting them online. They're a great resource and are very helpful for review before exams and tests."

"I really like how the lectures were recorded. I usually don't get everything in class 'cause I'm too busy copying things down. I can always go back to the recordings to catch the notes I missed in class and clarify the key concepts."

"The recorded lectures are excellent for reviewing certain sections that were not understood at the time during class. I also like how all the videos have the topic covered in the title so it's easier to go back the specific section needed."

\section{DISCUSSION}

Because of the very favorable feedback, the authors will continue using the MEETS and capture lectures in the coming years. Lecture capture will likely be extended to additional courses.

\section{REFERENCES}

1. Cleghorn, W.L. and Dhariwal, H. $3^{\text {rd }}$ Int Sym for Eng Ed, 2010. 2. von Konsky, B.R., Ivins, J., Gribble, S.J., 2009, Aust J of Ed Tech, $25,581-595$.

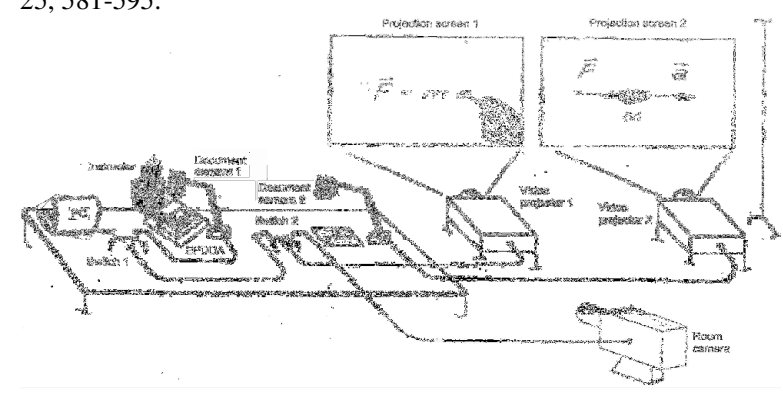

Figure 1: Layout of the MEETS 